\title{
Evolution of the Arctic Ocean Salinity, 2007-08: Contrast between the Canadian and the Eurasian Basins
}

\author{
Camille Lique, ${ }^{*}$ Gilles Garric, ${ }^{+}$Anne-Marie Treguier, ${ }^{\#}$ Bernard BARnier, ${ }^{@}$ \\ NiCOLAS FERRY, \& CHARlES-EMMANUEl TESTUT, \& AND FANNY GIRARD-ARDHUIN** \\ * Laboratoire de Physique des Oceans, CNRS-IFREMER-IRD-UBO, Brest, France \\ ${ }^{+}$Mercator-Ocean, Toulouse, France \\ \# LPO, CNRS-IFREMER-IRD-UBO, Brest, France \\ ${ }^{\circledR}$ LEGI, CNRS-INPG-UJF, Grenoble, France \\ ${ }^{\&}$ Mercator-Ocean, Toulouse, France \\ ** IFREMER, Laboratoire d'Oceanographie Spatiale, Brest, France
}

(Manuscript received 1 April 2010, in final form 17 November 2010)

\begin{abstract}
The authors investigate the variability of salinity in the Arctic Ocean and in the Nordic and Labrador Seas over recent years to see how the freshwater balance in the Arctic and the exchanges with the North Atlantic have been affected by the recent important sea ice melting, especially during the 2007 sea ice extent minimum. The Global Ocean Reanalysis and Simulations (GLORYS1) global ocean reanalysis based on a global coupled ocean-sea ice model with an average of 12-km grid resolution in the Arctic Ocean is used in this regard. Although no sea ice data and no data under sea ice are assimilated, simulation over the 2001-09 period is shown to represent fairly well the 2007 sea ice event and the different components accounting for the ocean and sea ice freshwater budget, compared to available observations. In the reanalysis, the 2007 sea ice minimum is due to an increase of the sea ice export through Fram Strait $(25 \%)$ and an important sea ice melt in the Arctic (75\%). Liquid freshwater is accumulated in the Beaufort gyre after 2002, in agreement with recent observations, and it is shown that this accumulation is due to both the sea ice melt and a spatial redistribution of the freshwater content in the Canadian Basin. In the Eurasian Basin, a very contrasting situation is found with an increase of the salinity. The effect of the sea ice melt is counterbalanced by an increase of the Atlantic inflow and a modification of the circulation north of Fram Strait after 2007. The authors suggest that a strong anomaly of the atmospheric conditions was responsible for this change of the circulation.
\end{abstract}

\section{Introduction}

The Arctic Ocean is the main reservoir of freshwater $(\mathrm{FW})$ in the World Ocean, as it collects and stores large amounts of freshwater received mainly from large river discharge, inflow of low salinity water from the Pacific Ocean through Bering Strait, and net precipitation over the Arctic Basin. The freshwater is then released to the North Atlantic, as sea ice and low salinity water export along both sides of Greenland, through the Davis and Fram Straits. This freshwater balance of the Arctic Ocean has received much attention in recent years, as we expect that just a small change of one component of the freshwater

Corresponding author address: Camille Lique, Laboratoire de Physique des Oceans, CNRS-IFREMER-IRD-UBO, UMR 6523, IFREMER, BP 70, 29280 Plouzane, France.

E-mail: camille.lique@ifremer.fr budget could affect the strength of the Atlantic meridional overturning circulation (e.g., Aagaard and Carmack 1989; Jones and Anderson 2008) and therefore possibly modulate the global climate. Serreze et al. (2006) have recently presented a summary of the current estimations from observations (or from model results when observations were not available) of the different sources and sinks of freshwater for the Arctic Ocean. In their paper, they underline the lack of long-term measurements for most of the freshwater budget components, which makes it difficult to know the variability of the different terms or to detect their possible long-term trend. However, substantial changes seem to have recently affected different components of the Arctic freshwater system, such as an intensification of the hydrological cycle [increases of river discharge, Greenland ice melting, and precipitation; see for instance Peterson et al. (2006)] or changes in the Arctic hydrographic properties (e.g., Steele and Boyd 1998; Swift et al. 2005). A 
synthesis of the observed changes in the Arctic freshwater system over the last century can be found in White et al. (2007).

The only well-observed component of the Arctic freshwater system is probably the sea ice cover. From satellite records, Cavalieri et al. (2003) reported on a large decline of the sea ice extent since the late 1970s, which strongly accelerated over the last decade. At the end of the summer in 2007, the Arctic sea ice retreated to an unprecedented minimum during the nearly 30 years of satellite observations (Comiso et al. 2008), the sea ice extent being $25 \%$ lower than during the previous minimum record in September 2005 (Fig. 2a). This new record is related to a number of factors, including atmospheric conditions as well as a preconditioning of the sea ice, owing to the thinning of multiyear sea ice or the replacement of multiyear ice by first-year ice in previous years (Drobot et al. 2008; Zhang et al. 2008). Over the same period, the sea ice thickness also strongly decreased (Rothrock et al. 1999; Kwok et al. 2009), even though this quantity remains poorly observed, which makes it difficult to evaluate from observations the variability of the sea ice volume in the Arctic.

In the present study, we use the Global Ocean Reanalysis and Simulations (GLORYS1) global ocean reanalysis (Ferry et al. 2010), which covers the period 2002-08, to map changes in Arctic salinity, to quantify the amount of freshwater corresponding to the 2007 sea ice melt, and to compare the state of the Arctic freshwater balance before and after this event so as emphasize its possible impact for the Arctic Ocean or the subarctic region.

\section{GLORYS1: 2002-08 global ocean reanalysis}

In this study we use GLORYS1 global ocean reanalysis (Ferry et al. 2010), which is a global ocean eddy-permitting model simulation constrained by data assimilation produced in the framework of the French GLORYS project and the MyOcean European FP7 project. We present in the following the main features of the model and the data assimilation scheme used in GLORYS1V1 reanalysis.

The global ORCA025 coupled ocean-sea ice model configuration described in Barnier et al. (2006) is used to perform the reanalysis. It is based on the Nucleus for European Modelling of the Ocean (NEMO) numerical framework version 1.09. (Madec 2008), including the Louvain-la-Neuve Sea-Ice Model, version 2 (LIM2) sea ice model. Note that the standard LIM2 version described in Fichefet and Morales Maqueda (1997) has been improved here by including the Elastic-Viscous-Plastic (EVP) dynamics of the ice (Hunke and Dukowicz 1997) and computing the ocean-ice stress at each time step. This model configuration uses a global tripolar grid with $1442 \times 1021$ grid points and 50 vertical levels. Vertical grid spacing is finer near the surface $(1 \mathrm{~m})$ and increases with depth to $450 \mathrm{~m}$ at the bottom. Horizontal resolution is $27.75 \mathrm{~km}$ at the equator, $13.8 \mathrm{~km}$ at $60^{\circ} \mathrm{N}$, and gets to $10 \mathrm{~km}$ in the Arctic Ocean.

The simulation runs from October 2001 to February 2009 with assimilation of oceanic data. The ocean is initialized from rest with temperature and salinity distributions from the Analyse,Reconstruction et Indicateurs de la Variabilité Océanique (ARIVO) 2005 climatology (Gaillard and Charraudeau 2008). The sea ice is initialized from a snapshot (2 October 2001) of a longer simulation performed by the DRAKKAR project (ORCA025-G70, Lique et al. 2009). The surface forcing is based on daily atmospheric fields from the operational ECMWF analysis and forecasts (1-day averages) with corrections of tropical rainfalls (Troccoli and Kallberg 2004; Garric 2006). The Coupled Large-Scale Ice Ocean (CLIO) bulk formulation (Goosse et al. 2001) is used to evaluate the atmosphereocean and atmosphere-sea ice fluxes as in Barnier et al. (2006). In particular, details about the coupling between ocean and sea ice could be found in Goosse et al. (2001). River runoff rates are prescribed using the Dai and Trenberth (2002) climatological dataset. A relaxation of sea surface salinity to the Polar Science Center Hydrographic Climatology (PHC) monthly climatology (Steele et al. 2001) is added under sea ice, and the coefficient $\left(0.25 \mathrm{~m} \mathrm{day}^{-1}\right)$ amounts to a decay time of 40 days for $10 \mathrm{~m}$ of water depth.

The ocean model is constrained by the Mercator-Océan data assimilation system version 2 , which is a reducedorder Kalman filter following the SEEK formulation (Pham et al. 1998) used in numerous ocean eddy-permitting simulations (e.g., Testut et al. 2003; Tranchant et al. 2008). This approach has been used for several years at MercatorOcéan and has been implemented in different ocean model configurations like the PSY 3 V $21 / 4^{\circ}$ global ocean operational analysis forecasting system. The SEEK formulation requires knowledge of the forecast error covariance of the control vector. In GLORYS1, this vector is composed of the barotropic height field and the threedimensional temperature, salinity, and zonal and meridional velocity fields. The forecast error covariance is based on the statistics of a collection of ocean state anomalies (typically 300) and is seasonally dependent. The length of the assimilation cycle is 7 days and the data assimilation produces, after each analysis, global increments for the ocean barotropic height, temperature, salinity, and zonal and meridional velocity. An incremental analysis update (IAU) method (Bloom et al. 1996) is used to apply the increment to reduce the spinup effects after the analysis time. The reader is referred to Ferry et al. (2010) for a more 
TABLE 1. Arctic Ocean freshwater budget from different sources: all FW fluxes $\left(\mathrm{km}^{3} \mathrm{yr}^{-1}\right)$. Means are calculated from monthly output with $S_{\text {ref }}=34.8 \mathrm{psu}$ as a reference salinity. The sign convention is such that a source of freshwater for the Arctic Ocean is a positive value. Atmospheric forcing is the sum of the two terms: $P-E\left(2744 \mathrm{~km}^{3} \mathrm{yr}^{-1}\right)$ and the damping $\left(410 \mathrm{~km}^{3} \mathrm{yr}^{-1}\right)$. Results from Lique et al. (2009) and from observations are also shown for comparison. All observational values are taken from Serreze et al. (2006) who provide "best" estimates among the different values given in the literature, except for the flux through Davis Strait, which are based on Cuny et al. (2005). Note that the value indicated here for model estimation of the freshwater flux through Davis Strait differs from the value given in Lique et al. (2009) as we include in this term the contribution of the connection with Hudson Bay, which is open by one grid point (contrary to what was said in Lique et al. 2009, their Table 1). Over a long period (1965-2002) the sum of the budgets terms $\left(168 \mathrm{~km}^{3} \mathrm{yr}^{-1}\right) \mathrm{roughly}$ equals the freshwater content change between January 1965 and December $2002\left(95 \mathrm{~km}^{3} \mathrm{yr}^{-1}\right)$.

\begin{tabular}{|c|c|c|c|}
\hline & 2002-06 Avg & 1965-2002 Avg From Lique et al. (2009) & Obs \\
\hline Atmospheric forcing & 3154 & 3119 & 2000 \\
\hline Runoffs & 3688 & 3406 & 3200 \\
\hline \multicolumn{4}{|c|}{ Ocean transport } \\
\hline Bering Strait & 2889 & 3021 & 2500 \\
\hline Davis Strait & -4390 & -4345 & -3500 \\
\hline Fram Strait & -1230 & -1990 & -2400 \\
\hline Barents Sea opening & -719 & -255 & -90 \\
\hline Total & -3450 & -3569 & -3490 \\
\hline \multicolumn{4}{|c|}{ Ice transport } \\
\hline Bering Strait & 205 & 132 & 100 \\
\hline Davis Strait & -341 & -539 & -410 \\
\hline Fram Strait & -940 & 2179 & -2300 \\
\hline Barents Sea opening & -47 & -201 & - \\
\hline Total & -1123 & -2788 & -2810 \\
\hline
\end{tabular}

detailed description of the simulation, data assimilation method, and validation.

The assimilated observations are sea surface temperature (SST) maps from the daily National Centers for Environmental Prediction (NCEP) Real-Time Global (RTG) $1 / 2^{\circ}$ product (Thiebaux et al. 2003); alongtrack altimetric data provided by Segment Sol multimission d'Altimétrie, d'Orbitographie et de localisation précise/Developing Use of Altimetry for Climate Studies (SSALTO/DUACS) originating from TOPEX/Poseidon, ERS-2, Geosat FollowOn (GFO), Envisat, and Jason-1 satellites; and in situ temperature and salinity profiles [including XBTs, CTDs, Argo data, Tropical Ocean and Global Atmosphere (TOGA)/Tropical Atmosphere Ocean (TAO), and Prediction and Research Moored Array in the Tropical Atlantic (PIRATA) moorings, etc.] from the CORA02 in situ database distributed by Coriolis Global Data Assembly Center (available online at http://www.coriolis.eu.org/cdc/).

It is worth noting that under the sea ice and or when the observed SST is below $-1^{\circ} \mathrm{C}$ no data is assimilated at all. Thus, no in situ profile is assimilated within the Arctic domain studied, except near the Alaskan Arctic coast during summer 2008 where a few XBTs are assimilated during summer. However, we checked that the salinity increments are weak and do not contribute significantly to the Arctic freshwater budget. Thus, the Arctic region in GLORYS1 reanalysis can be considered as a "free" regional model forced with reanalyzed boundary conditions, in which the only constraint by the observations is the sea surface salinity restoring under sea ice.

We first evaluate the capacity of GLORYS1 global ocean reanalysis at reproducing the observed Arctic sea ice extent, especially the 2007 minimum (Fig. 2a and the following section), as well as its performance at simulating the Arctic freshwater system (Table 1). We define the Arctic Ocean as the area enclosed by the following transects across ocean straits: Bering Strait, a section across the Barents Sea between Norway and Svalbard Island (following the $20^{\circ} \mathrm{E}$ meridian), Fram Strait, and Davis Strait (Fig. 1).

The definitions used in this study for the freshwater content (FWC) and the freshwater fluxes are similar to the one used in Lique et al. (2009) with the same reference salinity of 34.8 psu. The total freshwater content stored in our domain is thus computed as

$$
\begin{aligned}
\mathrm{FWC} & =\mathrm{FWC}_{\text {liq }}+\mathrm{FWC}_{\text {ice }} \\
& =\iiint \frac{S_{\text {ref }}-S}{S_{\text {ref }}} d V+\frac{S_{\text {ref }}-S_{\text {ice }}}{S_{\text {ref }}} \times V_{\text {ice }} \times \frac{\rho_{\text {ice }}}{\rho_{\text {water }}},
\end{aligned}
$$

where $V$ is the volume of the domain; $S$ is the salinity calculated by GLORYS1; $S_{\text {ref }}$ is the reference salinity; $S_{\text {ice }}$ is the sea ice salinity (constant and equal to $6 \mathrm{psu}$ ); $V_{\text {ice }}$ is the sea ice volume; $\rho_{\text {ice }}$ is the sea ice density $\left(900 \mathrm{~kg} \mathrm{~m}^{-3}\right)$; and $\rho_{\text {water }}$ is the density of water $\left(1000 \mathrm{~kg} \mathrm{~m}^{-3}\right)$. 


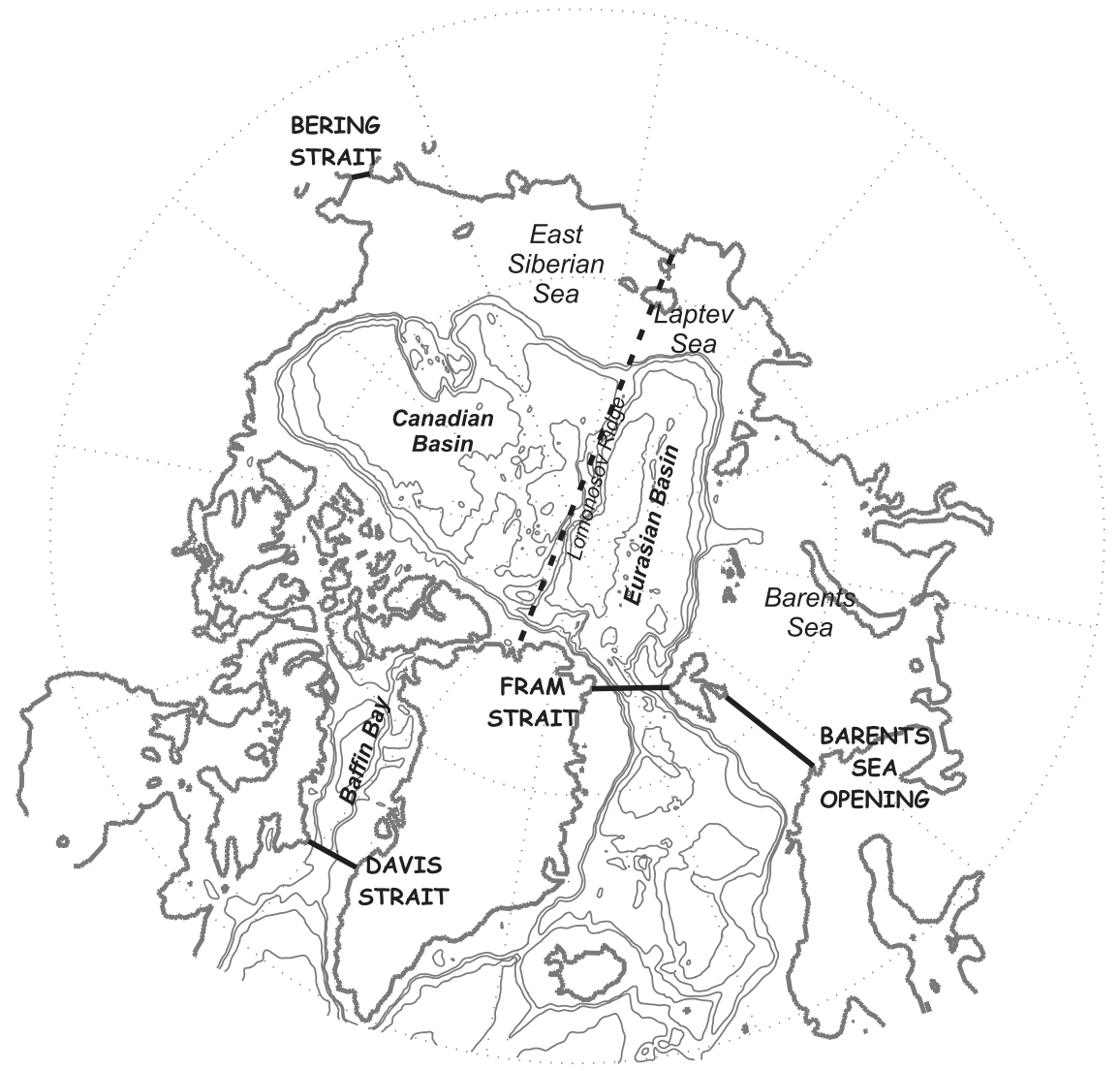

FIG. 1. Arctic Ocean and localization of the main place names used in the text. The domain is enclosed by four sections: the Bering Strait, the Davis Strait, the Fram Strait, and the Barents Sea opening. The dotted line indicates the separation between the Canadian and Eurasian Basins along the Lomonosov Ridge. Bathymetry contours at 500, 1000, 2000, 3000, 4000, and $5000 \mathrm{~m}$ are drawn with a thin line. The 500-m contour delimits the shelves from the interior of the basins.

The values for the 2002-06 average of the different components accounting for the Arctic freshwater balance are listed in Table 1. In a previous paper, we analyzed the variability of the Arctic freshwater budget over the period from 1965 to 2002 in a simulation run with a setup similar to the same model without assimilation of observations and a different atmospheric forcing (Lique et al. 2009). Results from observations and from this previous study are also shown for comparison. The simulated Arctic freshwater budget of the GLORYS1 reanalysis for the recent period is in general agreement with the observational budget of Serreze et al. (2006) and comparable with the mean budget calculated by Lique et al. (2009). The main difference between the GLORYS1 results and the observational budget by Serreze et al. (2006) is the smaller simulated liquid and sea ice freshwater export through Fram Strait. However, this could be explained, at least partly, by the different periods used to average the fluxes. The time series of the sea ice and liquid freshwater exports through Fram Strait presented in Lique et al. (2009) shows periods when the sea ice and liquid freshwater contributions are as low as the GLORYS1 values. The freshwater flux through the Barents Sea opening given by the GLORYS1 reanalysis represents a larger sink of freshwater than in the observations and in the budget presented in Lique et al. (2009). The difference with the latter study is due to an overestimation of the Atlantic inflow intensity by about $1 \mathrm{~Sv}(\mathrm{~Sv} \equiv$ $10^{6} \mathrm{~m}^{3} \mathrm{~s}^{-1}$ ) more through the section. We examine the contribution to the surface forcing from the salinity restoring to the climatology. At a seasonal time scale, its variations are anticorrelated with the fluctuations of the sea ice-ocean flux, but its maximum remains smaller by about a factor of 5. Since the restoring acts as a damping, the variability for the freshwater content in the reanalysis is somehow smaller than it would be without restoring. Thus, this term is not driving an important part of the Arctic freshwater content variability in the reanalysis, even though its amplitude can be locally large, especially where and when the sea ice-ocean flux is large. The freshwater 
(a)
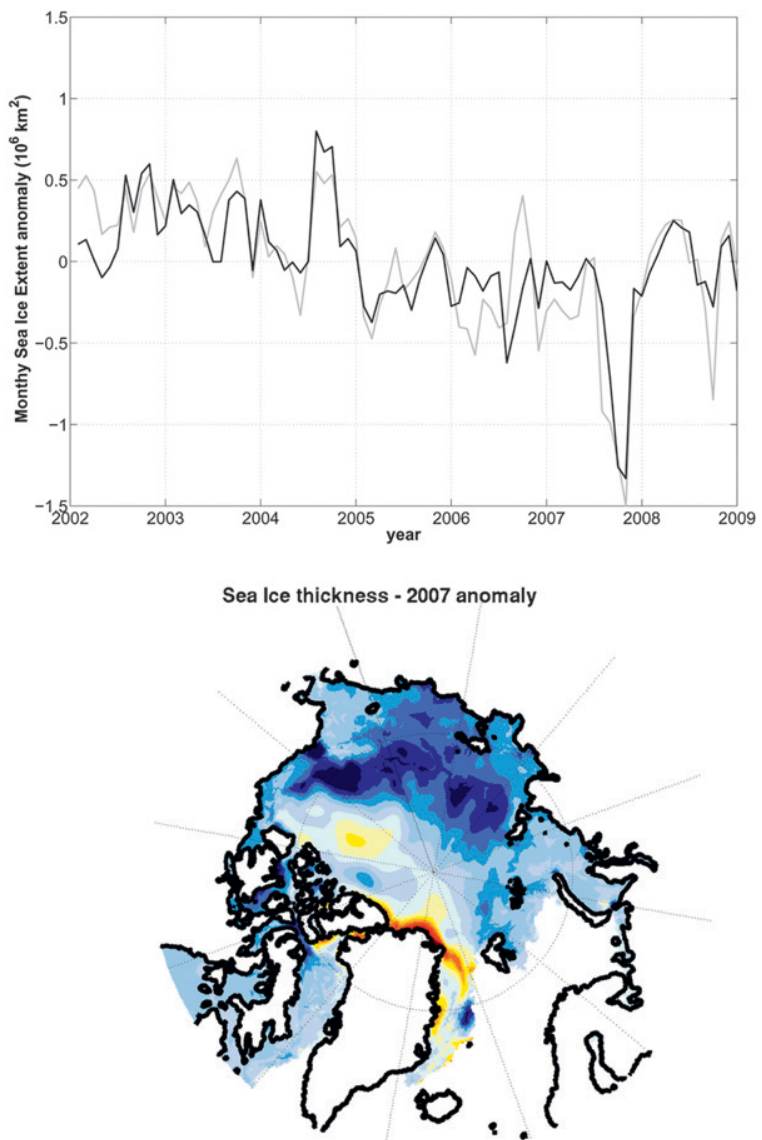

(c)

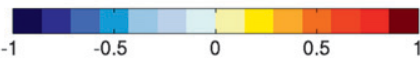

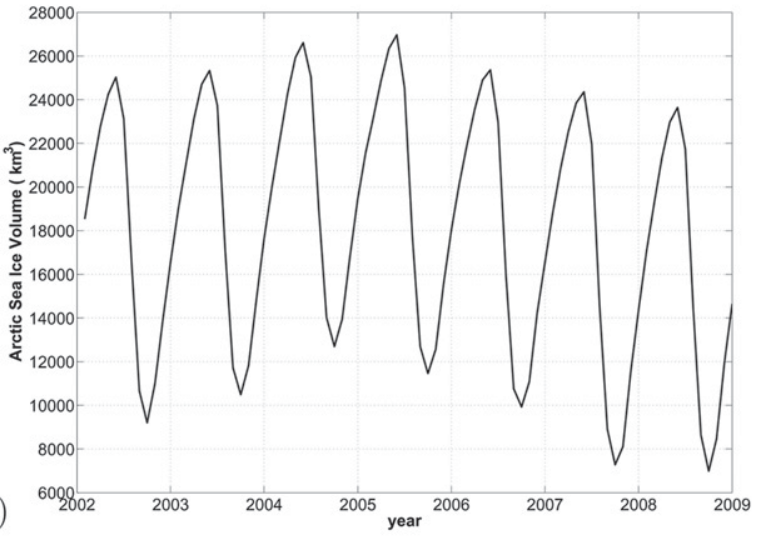

Sea Ice thickness -2008 anomaly

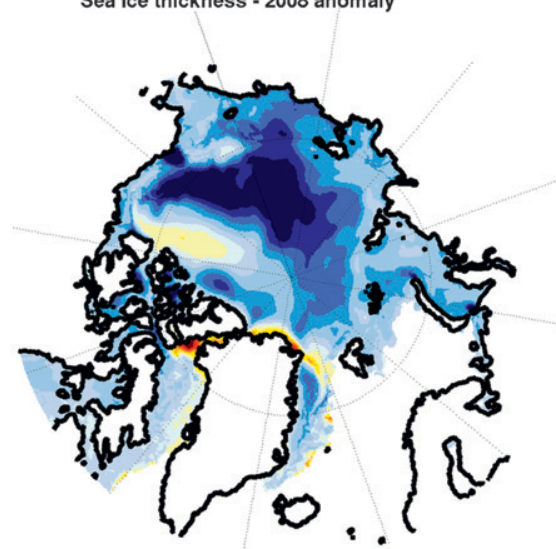

(d)

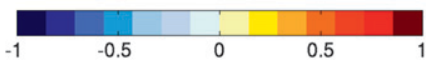

FIG. 2. GLORYS1 monthly Arctic sea ice extent (a) anomaly and (b) volume. The National Snow and Ice Data Center (NSIDC) observed sea ice extent is superimposed in gray for direct comparison (Fetterer et al. 2009). The sea ice volume can be compared to Kwok et al. (2009, Fig. 5). Sea ice thickness anomalies (m) in (c) 2007 and (d) 2008 are shown. "Anomaly" refers to the difference from the average over 2002-06.

budget averaged over 2002-06 is largely unbalanced, contrary to the budgets from Lique et al. (2009) and from observations. As the period considered here is short, we do not expect that the freshwater content (as liquid and sea ice forms) would remain constant. The accumulation sustained over 2002-06 is on the order of magnitude of what could be seen in some years in Fig. 6 of Lique et al. (2009). However, as the run starts in October 2001, we also acknowledge that part of this trend could be unrealistic and consists of the model initial adjustment.

\section{Quantification of the 2007 sea ice melt}

In September 2007, satellite observations of the sea ice extent have revealed that the Arctic sea ice extent has reached a record minimum of $4.1 \times 10^{6} \mathrm{~km}^{2}$ (Comiso et al. 2008). GLORYS1 reproduces the 2007 sea ice minimum fairly well, as well as the variability of the sea ice extent (Fig. 2a). The simulated monthly ice extent anomalies are highly correlated with satellite observations over 2002-08 $(r=0.84)$, even though the reanalysis globally overestimates the Arctic Sea ice extent by $7 \%$ on average.

Until now, there were only sparse observations both in time and space of the sea ice thickness, and it was thus difficult to validate the sea ice thickness and volume computed in numerical models. Recently, Kwok et al. (2009) provided one of the first estimates of the spatial distribution of sea ice thickness from 10 campaigns of the Ice, Cloud, and Land Elevation Satellite (ICEsat), and thus an estimation of the Arctic Sea ice volume over the recent period, even though the uncertainty remains huge on this quantity. When compared to satellite observations from Kwok et al. (2009, their Fig. 7), the reanalysis seems to capture well both the spatial pattern and the amplitude of the sea ice thickness, as well as their variability (not shown here). 
TABLE 2. Liquid and sea ice freshwater contents $\left(\mathrm{km}^{3}\right)$ and contribution from the Canadian and Eurasian Basins. In the Canadian Basin, contributions from the shelves and the interior are also indicated, the interior being defined by the area deeper then $500 \mathrm{~m}$. Means are calculated from monthly output, with a reference salinity $34.8 \mathrm{psu}$, and for the whole water column from the surface to the bottom (negative contributions of the liquid FW content are allowed). See Fig. 1 for the definitions of the two basins.

\begin{tabular}{|c|c|c|c|c|c|}
\hline & 2002-06 Avg & 2007 & 2007 Anomaly & 2008 & 2008 Anomaly \\
\hline \multicolumn{6}{|c|}{ Ice } \\
\hline Canadian Basin & 10398 & 9552 & -846 & 9241 & -1057 \\
\hline Interior & 6394 & 5806 & -588 & 5395 & -999 \\
\hline Shelves & 4004 & 3746 & -258 & 3846 & -58 \\
\hline Eurasian Basin & 3984 & 3212 & -772 & 3173 & -811 \\
\hline Subtotal & 14382 & 12764 & -1618 & 12414 & -1968 \\
\hline \multicolumn{6}{|c|}{ Liquid } \\
\hline Canadian Basin & 50424 & 51123 & +699 & 51464 & +1040 \\
\hline Interior & 26336 & 27693 & 1357 & 28244 & +1908 \\
\hline Shelves & 24088 & 23430 & -658 & 23220 & -868 \\
\hline Eurasian Basin & 1057 & -314 & -1371 & -738 & -1795 \\
\hline Subtotal & 51481 & 50809 & -672 & 50726 & -755 \\
\hline Total & 65863 & 63573 & -2290 & 63140 & -2723 \\
\hline
\end{tabular}

We thus use the GLORYS1 outputs to estimate the Arctic sea ice volume and its variability (Fig. 2b). The values and the tendency calculated from GLORYS1 are again similar to those found by Kwok et al. (2009, their Fig. 5f). From 2006 to 2007 the sea ice volume in the Arctic has decreased by $1566 \mathrm{~km}^{3}$ on a year average, and 471 additional $\mathrm{km}^{3}$ of sea ice volume has been lost between 2007 and 2008. It corresponds to an equivalent of 1248 and $375 \mathrm{~km}^{3}$ of freshwater, respectively, the conversion from sea ice volume to freshwater content being done following the definition given in the previous section. This is due to both a decrease of the sea ice extent (Fig. 2a) and of the sea ice thickness (Figs. 2c,d).

To have an idea of the freshwater signal magnitude due to the sea ice volume decrease (a loss of $1623 \mathrm{~km}^{3}$ of freshwater from 2006 to 2008), one can compare this quantity to the $2000 \mathrm{~km}^{3}$ anomaly of freshwater exported through Fram Strait in two years, which was estimated to be on the origin of the episode of the Great Salinity Anomaly (GSA) observed during the 1970s in the North Atlantic (Dickson et al. 1988). Hence, one could imagine that, if the total of the 2006-08 freshwater anomaly wasor about to be-exported to the North Atlantic, we could expect to observe a GSA-like signal in the subpolar region. We thus examine the Arctic freshwater budget for the year 2007 and 2008 relative to the 2002-06 period to track the freshwater signal corresponding to the sea ice melt and find out whether this anomaly has been absorbed into the Arctic Ocean or possibly exported to the subpolar region.

First of all, we determine the area where we can expect the most important impact for the sea ice melt. In GLORYS1, the export of sea ice increases in 2007 (compared to the 2002-06 average shown in Table 1) by
$25 \%$ through Fram Strait and 20\% through Davis Strait and thus 315 and 66 additional $\mathrm{km}^{3}$ of freshwater are respectively exported in this year. As the 2007 anomaly of freshwater content corresponding to sea ice is $1618 \mathrm{~km}^{3}$ lower than the 2002-06 average (Table 2), the increase of the sea ice export is responsible for about $25 \%$ of the sea ice freshwater content decrease, and thus sea ice melt accounts for the remaining $75 \%$. This is consistent with the result of Zhang et al. (2008), who find in their model that atmospheric conditions in 2007 lead to an increase of the ice volume export at Fram Strait, which is responsible for $30 \%$ of the 2007 sea ice volume decrease over the Arctic. The spatial pattern of the sea ice extent in September 2007 (both from satellite observations and from GLORYS1) suggests that the sea ice melt might have mostly occurred in the Canadian Basin. This is confirmed in our reanalysis as the ocean-sea ice flux increases mostly in the Canadian Basin while the sea ice is melting (not shown). This is also consistent with the sea ice thickness decrease in this part of the Arctic basin (Figs. 2c,d). In the following section, we look for the possible changes in salinity and freshwater content in this basin. We consider that the Canadian part of the Arctic Ocean is delimited by the Lomonosov Ridge, Bering Strait, and Davis Strait.

\section{Freshwater content changes in the Canadian Basin}

In two recent papers, Proshutinsky et al. (2009) and McPhee et al. (2009) provide an unprecedented description of spatial and temporal variability of the salinity in the Beaufort gyre from observations during the 2000s. They find an important accumulation of freshwater in the very recent years from 2003 to 2007 (Proshutinsky et al. 2009) 


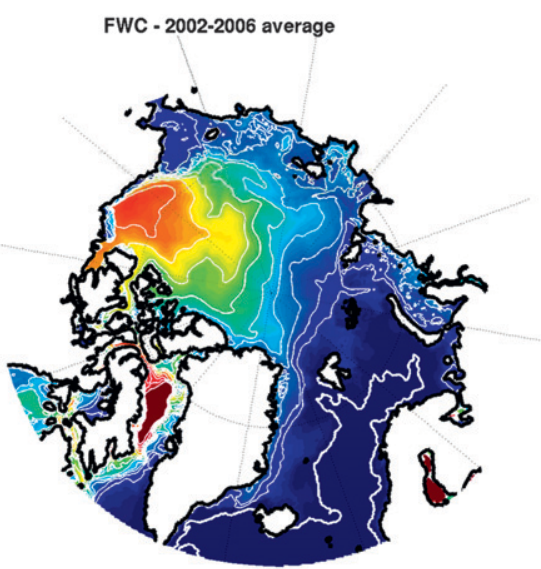

(a)

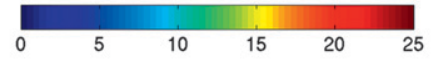

(b)
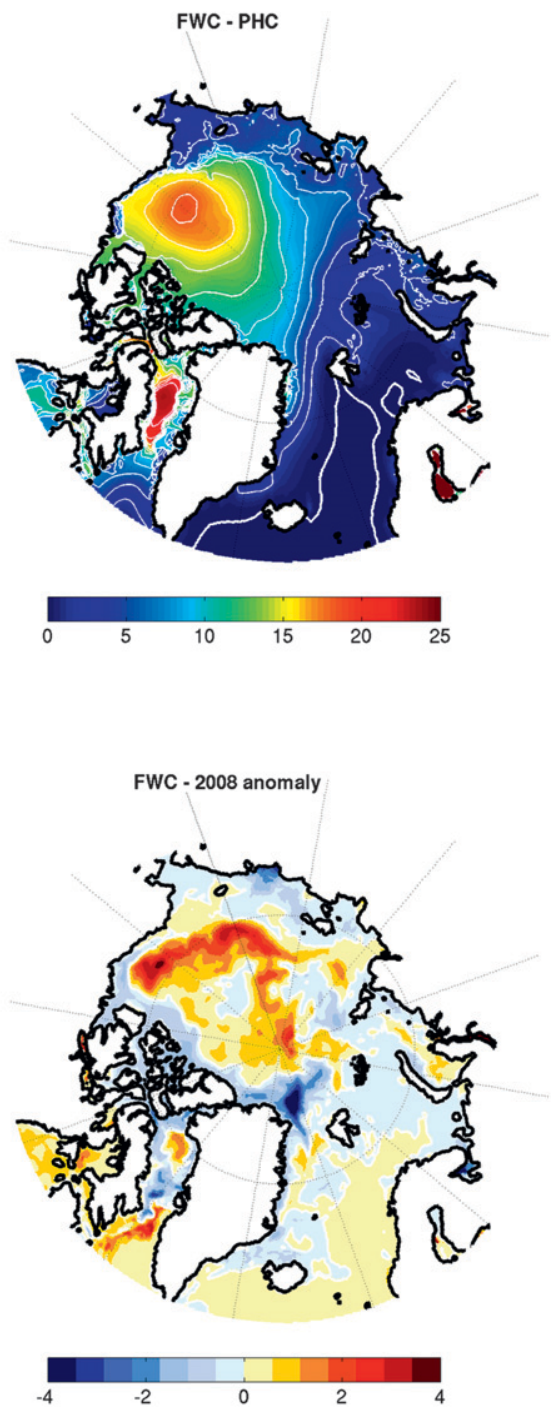

(d)

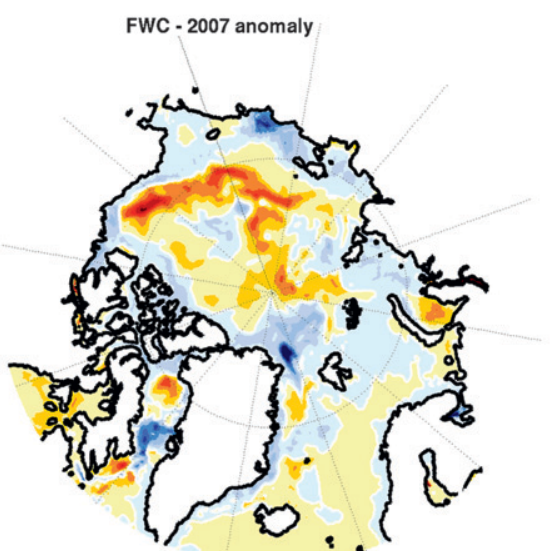

(c)

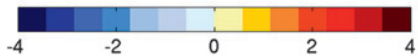

FIG. 3. (a),(b) Mean freshwater content (FWC) (thickness (m) from 2002 to 2006 model results and from PHC climatology, respectively. (c),(d) FWC anomalies (m) from model results (relative to 2002-06) for 2007 and 2008 , respectively.

and in 2008 (McPhee et al. 2009). One could expect that the freshwater increase in the Beaufort gyre would be related to the sea ice melt. However, both studies underline the predominant role of the atmospheric circulation for this freshwater accumulation: the Ekman-pumping process is enhanced during these years due to persistence of the Arctic high anticyclonic circulation.

Figure 3 shows the 2002-06 average freshwater content (Fig. 3a) and the 2007 (Fig. 3c) and 2008 (Fig. 3d) anomalies. To allow a direct comparison with Proshutinsky et al. (2009) and McPhee et al. (2009), freshwater content is computed from the surface to the uppermost level where the salinity equals the reference salinity $\left(S_{\text {ref }}=34.8 \mathrm{psu}\right)$. The freshwater content calculated from the PHC climatology (Steele et al. 2001) is also shown for comparison (Fig. 3b).
Compared to the PHC climatology, the GLORYS1 average (Fig. 3a) presents a similar spatial pattern (Fig. 3b), but the freshwater content in the Beaufort gyre is higher for the GLORYS1 average than in PHC. The difference could be explained by the fact that the climatology is heavily weighted toward the decades of the 1970s and 1980s when the freshwater content in the Beaufort gyre was shown to be smaller than in the 2000 s, as previously underlined by Proshutinsky et al. (2009). Despite the different period represented by GLORYS1 and PHC, the mean freshwater content calculated from both GLORYS1 and PHC shows that most of the freshwater in the Arctic is stored within the Beaufort gyre in the Canadian Basin.

Compared to the 2002-06 average, the freshwater content in the Beaufort gyre increases up to 3 and $4 \mathrm{~m}$ layer 
thickness in 2007 and 2008, respectively (Figs. 3c,d). Proshutinsky et al. (2009) and McPhee et al. (2009) observed very similar increases of the freshwater content in the Beaufort gyre in 2007 and 2008, respectively (see Fig. 9 in Proshutinsky et al. 2009 and Fig. 1 in McPhee et al. 2009). If we consider the whole water column (and thus allow a negative contribution to the liquid freshwater content), the Canadian Basin gains $699 \mathrm{~km}^{3}$ of liquid freshwater in 2007 , compared to the average, and $341 \mathrm{~km}^{3}$ more freshwater in 2008 (Table 2, these amounts are 573 and $307 \mathrm{~km}^{3}$ of freshwater if we choose to take the same definition as used for Fig. 3 and in Proshutinsky et al. 2009).

Hence, the variability of the total freshwater content is very small in the Canadian Basin, as the loss of freshwater from sea ice in this basin in 2008 compared to the $2002-06$ average $\left(-1057 \mathrm{~km}^{3}\right)$ is balanced by the gain of liquid freshwater in 2008 compared to the 2002 06 average $\left(+1040 \mathrm{~km}^{3}\right)$. The spatial patterns of the 2007 and 2008 freshwater content anomalies (Figs. 3c,d), as well as the quantification of the freshwater anomalies on the shelves and in the interior of the Canadian Basin (Table 2), are also consistent with the hypothesis of Proshutinsky et al. (2009) regarding the role of an increasing Ekman pumping for the accumulation of freshwater in the Beaufort gyre. In the reanalysis, the accumulation of freshwater in the Beaufort gyre occurs along with a salinization of the coastal area along the shelves. A strong negative anomaly (4-m decrease) is visible in the East Siberian Sea. Polyakov et al. (2008) also find an out-of-phase variability in the central Arctic basin and on the shelves as they analyzed the freshwater content variations over the last 100 years and conclude that freshwater anomalies generated on the shelves, and particularly in the East Siberian Sea, will be exported to the Central Basin where they tend to moderate the freshwater content changes. The pattern of the freshwater anomalies in 2007 and 2008 (Fig. 3) is consistent with their finding. Moreover, the salinization in the East Siberian Sea occurs along with a westward intensification of the wind stress along the coast (see the right column of Fig. 4). Following the scenario proposed by Steele and Ermold (2004), this westward intensification of the wind could have pushed relatively salty Pacific water along the coast in the East Siberian and Laptev Seas and may have caused the salinization. In GLORYS1, the Ekman pumping calculated from the wind stress fields increases in 2007 and 2008 in the Beaufort gyre (not shown), and this leads to a spatial redistribution of the freshwater in the Canadian Basin due to the enhanced intensity of the Beaufort gyre. We also find in our reanalysis a completely similar spatial distribution between the sea surface height (SSH) fields and the freshwater content fields, as previously suggested by Häkkinen and Proshutinsky (2004) to show the link between the freshwater content distribution in the Canadian Basin and the atmospheric conditions. Over a longer time period (1965-2002), we could not find any robust correlation between the freshwater content variations in the Arctic and SSH variations in the Beaufort gyre (Lique et al. 2009), which suggests that the mechanisms of an accumulation of freshwater in the gyre, which behaves as a flywheel, could be only intermittent. Note also that we are able to reproduce the amplitude of the freshwater accumulation in the Beaufort gyre without any interannual variability of river runoff, which make this source of freshwater for the Arctic an unlikely candidate to explain the freshwater increase. However, Polyakov et al. (2008) suggest that the variability of the river runoff inputs onto the Arctic shelves could be responsible at least for a part of freshwater content anomalies observed along the shelves that will be afterward exported to the central Arctic. Thus, the lack of interannual variability for the river runoff might lead to an overestimation of the freshening simulated in the Beaufort gyre. Last, as also suggested by Polyakov et al., we find that the net precipitation precipitation minus evaporation $(P-E)$ variations are by an order of magnitude too small (compared, for instance, to the sea ice-ocean flux) to lead to important changes of salinity in the Arctic. For instance, we find a negative anomaly for this term in 2007 in the Canadian Basin (relative to 2002-06 average).

We also examine the variability of the advective exchanges of freshwater with the subpolar region to detect possible changes linked with the freshening of the Arctic Ocean in the Canadian Basin. As the sea ice is mostly melting in the Canadian Basin, one could logically expect an increase of the freshwater export through the Canadian Arctic Archipelagos and through Davis Strait. However, the GLORYS1 2007 and 2008 anomalies of the liquid freshwater transport through Davis Strait are negative in $2007\left(-57 \mathrm{~km}^{3} \mathrm{yr}^{-1}\right)$ and very small in 2008 $\left(98 \mathrm{~km}^{3} \mathrm{yr}^{-1}\right)$. This is consistent with the study of Våge et al. (2009) that shows the observed freshwater transport through Davis Strait just slightly increases from 2004 to 2007, as it does in our simulation. Note that the constant freshwater export is consistent with the sustained wintertime convection in the Labrador Sea (the convection in the Labrador Sea is found to be deeper in GLORYS1 during the 2007/08 winter than previous winter, in agreement with the observations collected by Yashayaev and Loder 2009). In Lique et al. (2009), the variability of the liquid freshwater transport through Davis Strait was found to be driven by velocity fluctuations, the role of the salinity fluctuations being negligible. Similarly, Polyakov et al. (2008) conclude from the analysis of a large dataset of observations that the strength of the export of Arctic water controls the supply of Arctic 
PSI - 2002-2006 average

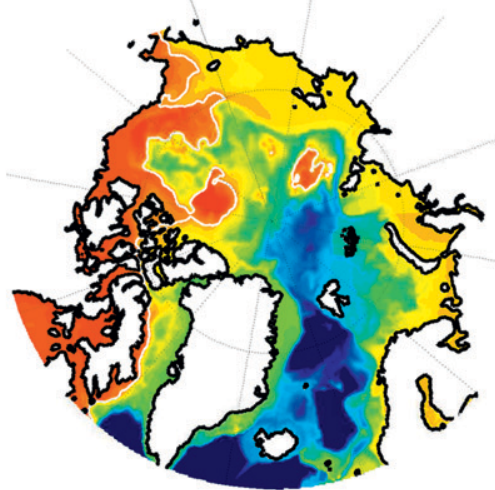

(a)
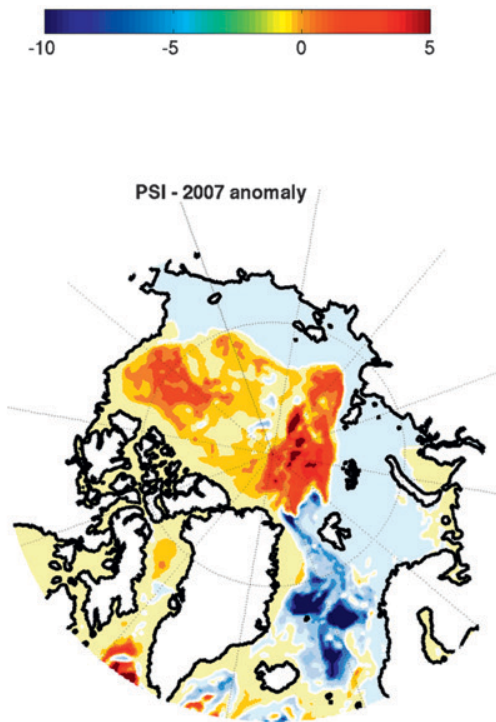

(c)

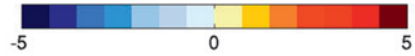

(d)

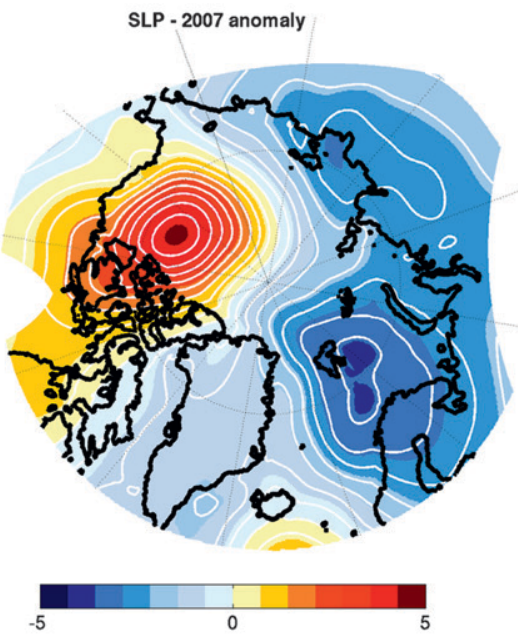

(b)
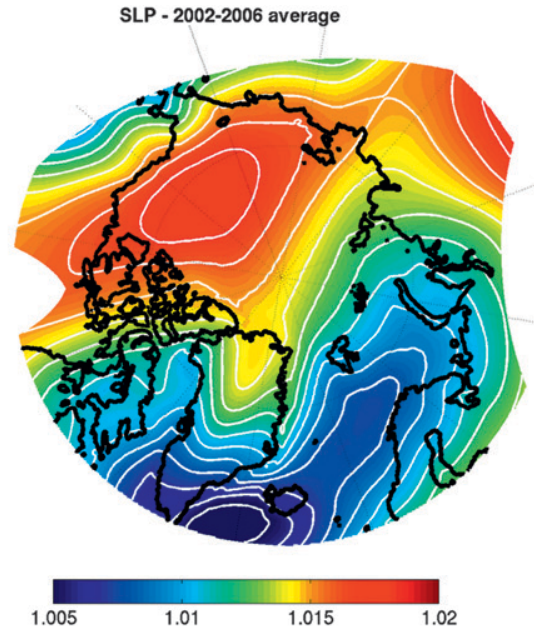

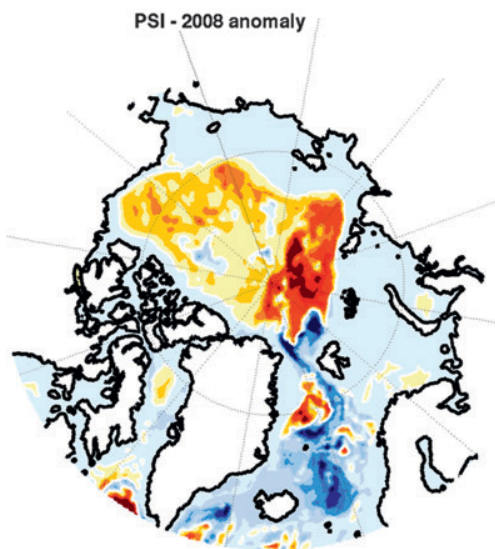

(e)

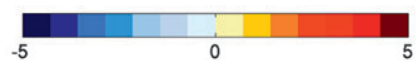

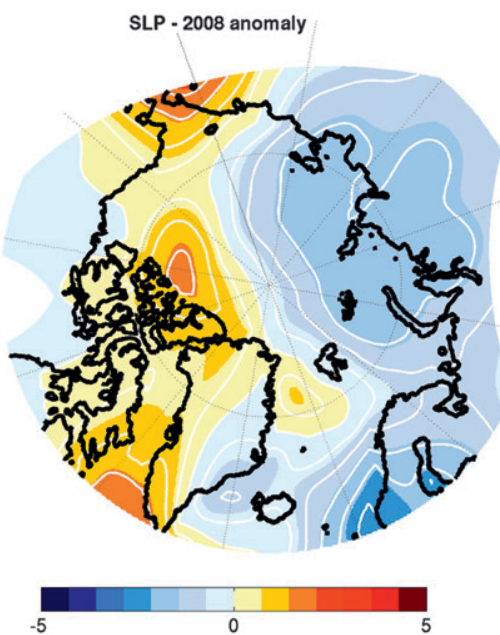

FIG. 4. Average over 2002-06 of (a) the barotropic streamfunction ( $\Psi, \mathrm{Sv}$ ) and (b) sea level pressure (SLP, hPa). (c),(d) 2007 and (e), (f) 2008 anomalies of $\Psi$ and SLP. "Anomaly" refers to the difference with the average over 2002-06; contour interval is $1 \mathrm{hPa}$ for SLP. 
freshwater to subpolar basins while the intensity of the Arctic Ocean salinity anomalies is of less importance. Thus, possible changes of salinity of the surface water in the Canadian Basin due to sea ice melting might not strongly modulate the liquid freshwater transport through Davis Strait. However, as a very important quantity of freshwater is accumulating and stocked in the Beaufort gyre, one might expect that a change in the atmospheric circulation [a change to a positive state of the Arctic Oscillation (AO)] could lead to a fast release of the freshwater and thus an increase of the freshwater export to the North Atlantic during the coming years, as suggested by Proshutinsky et al. (2009).

\section{Salinization of the Eurasian Basin}

Figures $2 \mathrm{c}$ and $2 \mathrm{~d}$ show that the sea ice thickness has also decreased in the Eurasian Basin in 2007 and 2008, suggesting a loss of sea ice in this basin and thus a transfer of freshwater from the sea ice to the ocean (as the sea ice export through Fram Strait does not increase substantially). When we quantify the sea ice loss, the sea ice melt represents a loss of $772 \mathrm{~km}^{3}$ of freshwater in 2007 and $39 \mathrm{~km}^{3}$ more in 2008 for the Eurasian Basin compared to the 2002-06 average (we consider the Eurasian Basin as that part of the Arctic Ocean to the east of the Lomonosov Ridge and closed by Fram Strait and the Barents Sea opening). However, contrary to the Canadian Basin, the liquid contribution of the freshwater content in this basin decreases as well in 2007 and 2008, the liquid freshwater content anomaly in 2008 being equal to $-1795 \mathrm{~km}^{3}$ of freshwater, that is, roughly twice as large as the decrease due to sea ice melt. McPhee et al. (2009) have observed a negative freshwater content anomaly in the Eurasian Basin in 2008 compared to the PHC climatology, but they conclude that this signal is negligible compared to the freshening of the Canadian Basin. However, this conclusion suffers from a very limited number of observations in the Eurasian Basin. In particular, they do not have any observations north of Fram Strait where our reanalysis results show the stronger signal of a salinization (Figs. 3c,d). We thus try to understand the origin of this signal, which appears from the surface to about $800 \mathrm{~m}$.

Figure 4 shows the 2002-06 average and the 2007 and 2008 anomalies of the barotropic streamfunction $(\Psi)$ and the sea level pressure (SLP) calculated from the ECMWF Re-Analysis (ERA)-Interim reanalysis. In the Eurasian Basin, we have a strong positive anomaly of $\Psi$ owing to an important decrease of the intensity of the gyre composed by the Atlantic inflow and the transpolar drift in the Arctic Ocean. In contrast, the strong negative anomaly in the Greenland Sea reveals an intensification of the gyre circulation in this basin, probably linked with the similar anomaly visible in the atmospheric fields. Hence, the water masses that flow with the Atlantic inflow through Fram Strait preferentially recirculate shortly just north of the strait, instead of penetrating farther into the Eurasian Basin. This strong anomaly of circulation is also coherent with Fig. 5 (top), as in GLORYS1 we have an increase of both northward and southward volume transports through Fram Strait after 2005, the net transport remaining roughly constant.

We then investigate the link between this anomaly of circulation and the signal of a negative freshwater content anomaly in the Eurasian Basin. In GLORYS1, the decrease of the freshwater flux corresponding to the saline Atlantic inflow through Fram Strait (Fig. 5) is completely due to an increase of the volume transport, the salinity remaining constant, which is qualitatively consistent with the very slight salinity decrease observed and reported in Holliday et al. (2009). On the other hand, the modeled southward freshwater flux through Fram Strait increases after 2005. In the reanalysis, as the short recirculation north of Fram Strait is enhanced, the water masses exiting at Fram Strait are directly coming from the Atlantic inflow, and thus these water masses do not undergo important modifications as they do not travel long inside the Arctic basin. Therefore, both salinity and volume transport of the outflowing branch increase, the resultant being a decrease of the freshwater export. With respect to that issue, GLORYS1 results seem to be inconsistent with the observational results of de Steur et al. (2009, their Fig. 2), who find a slight increase of the freshwater export through Fram Strait after 2005. However, they notice that freshwater anomalies were rather small when compared to the volume transport anomalies after 2005, the different behavior being due to deep volume transports increasing whereas the freshwater signal is negligible. In GLORYS1, both the surface and deeper volume transport increase (their contributions to the total volume transport anomaly are roughly equal) and this leads to an overestimation of the freshwater signal. Moreover, de Steur et al. (2009) use model output to estimate the contribution of the freshwater export on the shelves and find that this contribution increase after 2006, thus counterbalancing the decrease of the contribution of freshwater export in the core of the East Greenland Current (EGC). We have found in a previous paper, Lique et al. (2010), that the resolution of our model was not sufficient to represent properly the current on the shelves from the Bering Strait to Fram Strait and on the eastern coast of Greenland. Hence, we are not able to reproduce the contribution of the freshwater export on the shelves that could be important as well to moderate the freshwater transport signal. 


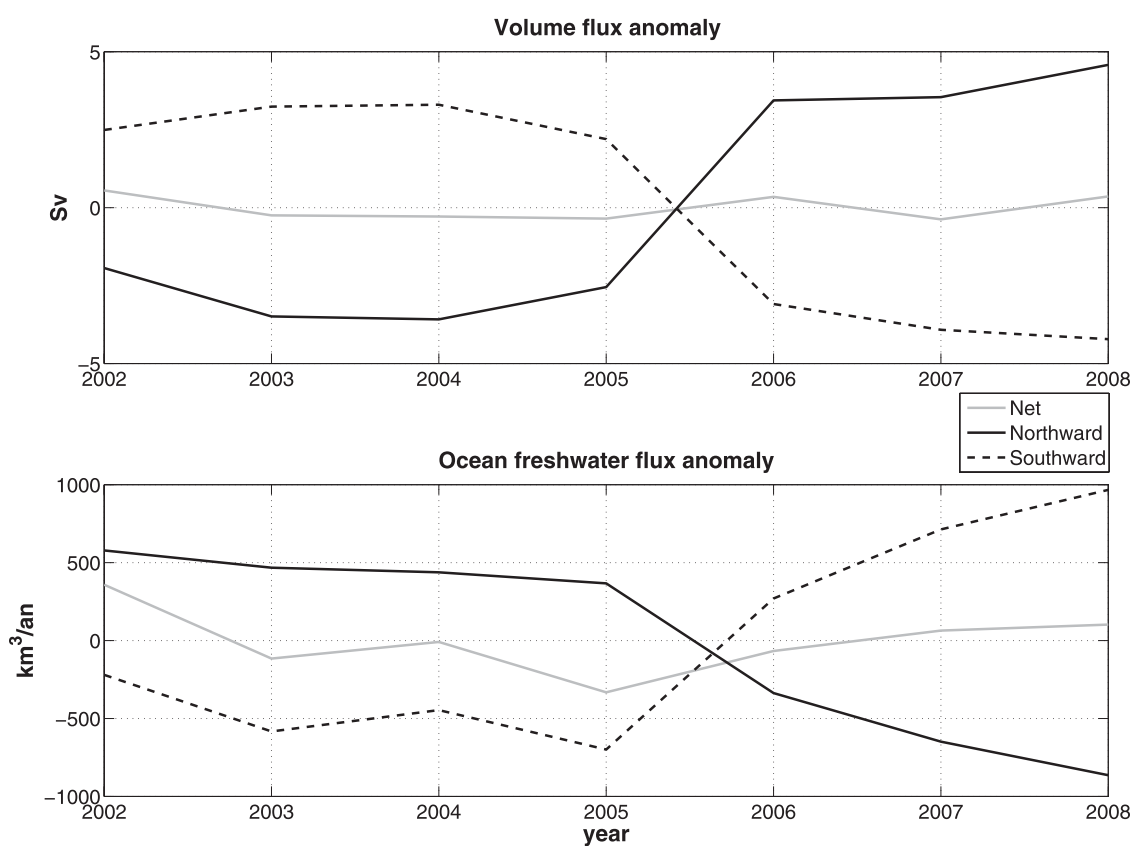

FIG. 5. Anomaly (relative to 2002-08) of (top) the mass flux and (bottom) the freshwater flux through Fram Strait. Net fluxes as well as northward and southward contributions are indicated. A positive mass flux goes northward, and a positive freshwater flux is a source of FW for the Arctic.

The increasing Atlantic inflow through Fram Strait (and the associated anomaly of circulation) leads to a very local salinization north of Fram Strait, while the freshwater content in the central Arctic remains constant: this is consistent with the results of Polyakov et al. (2008) as they find that the freshwater anomalies in the central Arctic cannot be explained by the variations of the Atlantic inflow.

\section{Conclusions}

Overall, in the GLORYS1 reanalysis, the Arctic Ocean is getting saltier in 2007 and 2008 compared to the 2002-06 average. However, the two basins present very contrasting situations. In the Canadian Basin, the total freshwater content remains roughly constant, as the quantity of freshwater equivalent to sea ice melt is transferred to the ocean through a gain of liquid freshwater. We also find a spatial redistribution of the freshwater in this basin, as atmospheric conditions lead to an enhanced Beaufort gyre where the freshwater is accumulated, which is fully consistent with recent observations in this region (Proshutinsky et al. 2009; McPhee et al. 2009). At the same time, the coastal regions in the Canadian Basin undergo salinization and the liquid and sea ice freshwater export on the western side of Greenland remains constant in 2007 and 2008. This out-of-phase variability of the freshwater content in the central Arctic and along the shelves was reported by Polyakov et al. (2008) as they analyzed a large dataset of observations over the last 100 years.

On the other side of the Lomonosov Ridge, the picture is different: both the sea ice and the liquid contributions of the freshwater content decrease in 2007 and 2008. In GLORYS1, we have a strong signal of a salinization north of Fram Strait (where no measurements where done recently). We show that this signal is due to an anomaly of the circulation, as the short recirculation of the Atlantic inflow north of Fram Strait is enhanced after 2006, possibly due to an intensification of the cyclonic gyre in the Greenland Sea linked with a similar anomaly in the atmospheric circulation. Hence, both net inflow and outflow though Fram Strait are intensified. More salty water enters the Arctic through Fram Strait and, as these water masses recirculate shortly without being modified, the export of liquid freshwater decreases as well. However, the GLORYS1 reanalysis does not reproduce the very fresh coastal current on the Greenland shelves, whose contribution has been observed to increase after 2006 and hence counterbalances the decrease of liquid freshwater export within the EGC core (de Steur et al. 2009).

We thus suggest that special atmospheric conditions in 2007 and 2008 (with a strong anomaly over both the Beaufort gyre and Greenland Sea) could have caused a spatial redistribution of the liquid freshwater in the Arctic 
Ocean. The current observation system in the Beaufort gyre designed to monitor changes of the freshwater storage in the Arctic seems to be able to capture a part of the freshwater content variability in the Arctic (the accumulation of freshwater in the Beaufort gyre). However, our results show that this observation system does not capture an important part of the freshwater content change signal: thus the current monitoring system should be extended to the Eurasian Basin where we found the larger signal and where no measurement is currently done. Moreover, our results back up the idea suggested by Proshutinsky et al. (2009) that a return to more neutral atmospheric conditions could lead to a release of the freshwater accumulated in the Beaufort gyre to the North Atlantic and, thus, possibly cause a new GSA in the future. The monitoring of the freshwater storage in the Beaufort gyre seems to be a good way to possibly predict such a signal in the future, as the GSA needs several years to propagate into the North Atlantic (e.g., Belkin 2004).

Acknowledgments. The realization of GLORYS1 global ocean reanalysis had the benefit of the grants that Groupe Mission Mercator Coriolis, Mercator-Ocean, and INSUCNRS attributed to the GLORYS project, and the support of the European Union FP7 via the MYOCEAN project. Computations were performed with the support of Météo-France HPC Center. C. Lique is supported by a Ph.D. grant from CNES and IFREMER. A. M. Treguier and $\mathrm{B}$. Barnier are supported by CNRS.

\section{REFERENCES}

Aagaard, K., and E. Carmack, 1989: The role of sea ice and other freshwater in the Arctic circulation. J. Geophys. Res., 94, 14 485-14 498.

Barnier, B., and Coauthors, 2006: Impact of partial steps and momentum advection schemes in a global ocean circulation model at eddy permitting resolution. Ocean Dyn., 56, 543-567.

Belkin, I. M., 2004: Propagation of the "Great Salinity Anomaly" of the 1990s around the northern North Atlantic. Geophys. Res. Lett., 31, L08306, doi:10.1029/2003GL019334.

Bloom, S. C., L. L. Takacs, A. M. Da Silva, and D. Ledvina, 1996: Data assimilation using incremental analysis updates. Mon. Wea. Rev., 124, 1256-1271.

Cavalieri, D. J., C. L. Parkinson, and K. Y. Vinnikov, 2003: 30-year satellite record reveals contrasting Arctic and Antarctic decadal sea ice variability. Geophys. Res. Lett., 30, 1970, doi:10.1029/ 2003 GL018031.

Comiso, J. C., C. L. Parkinson, R. Gersten, and L. Stock, 2008: Accelerated decline in the Arctic sea ice cover. Geophys. Res. Lett., 35, L01703, doi:10.1029/2007GL031972.

Cuny, J., P. B. Rhines, and R. Kwok, 2005: Davis Strait volume, freshwater and heat fluxes. Deep-Sea Res. I, 52, 519-542.

Dai, A., and K. Trenberth, 2002: Estimates of freshwater discharge from continents: Latitudinal and seasonal variations. J. Hydrometeor., 3, 660-687.

de Steur, L., E. Hansen, R. Gerdes, M. Karcher, E. Fahrbach, and J. Holfort, 2009: Freshwater fluxes in the East Greenland
Current: A decade of observations. Geophys. Res. Lett., 36, L23611, doi:10.1029/2009GL041278.

Dickson, R. R., J. Meincke, S. A. Malmberg, and A. J. Lee, 1988: The Great Salinity Anomaly in the North Atlantic. Nature, 256, 479-482.

Drobot, S., J. Stroeve, J. Maslanik, W. Emery, C. Fowler, and J. Kay, 2008: Evolution of the 2007-2008 Arctic sea ice cover and prospects for a new record in 2008. Geophys. Res. Lett., 35, L19501, doi:10.1029/2008GL035316.

Ferry, N., L. Parent, G. Garric, B. Barnier, and N. C. Jourdain, 2010: Mercator Global Eddy Permitting Ocean Reanalysis GLORYS1V1: Description and results. Mercator-Ocean Quarterly Newsletter, No. 36, Mercator Ocean Office, Toulouse, France, 15-27.

Fetterer, F., K. Knowles, W. Meier, and M. Savoie, cited 2009: Sea ice index. National Snow and Ice Data Center. [Available online at http://nsidc.org/data/seaice_index/.]

Fichefet, T., and M. A. Morales Maqueda, 1997: Sensitivity of a global sea ice model to the treatment of ice thermodynamics and dynamics. J. Geophys. Res., 102, 12 609-12 646.

Gaillard, F., and R. Charraudeau, 2008: New climatology and statistics over the global ocean. Mersea Project Rep. CNRSSTR-001 Del 5.4.7, 26 pp.

Garric, G., 2006: News: Surface freshwater balance for global Mercator-Ocean analysis purposes. Mercator-Ocean Quarterly Newsletter, No. 21, Mercator-Ocean Office, Toulouse, France, 3-6.

Goosse, H., J. M. Campin, E. Deleersnijder, T. Fichefet, P. P. Mathieu, M. A. Morales Maqueda, and B. Tartinville, cited 2001: Description of the CLIO model version 3.0. [Available online at http://www.astr.ucl.ac.be/index.php?page =CLIO.]

Häkkinen, S., and A. Proshutinsky, 2004: Freshwater content variability in the Arctic Ocean. J. Geophys. Res., 73, C03051, doi:10.1029/2003JC001940.

Holliday, N. P., S. L. Hughes, and A. Beszczynska-Möller, 2009: ICES report on Ocean Climate 2008. ICES Rep. 298, 68 pp.

Hunke, E. C., and J. K. Dukowicz, 1997: An elastic-viscous-plastic model for sea ice dynamics. J. Phys. Oceanogr., 27, 1849-1867.

Jones, E. P., and L. G. Anderson, 2008: Is the global conveyor belt threatened by Arctic Ocean fresh water outflow? ArcticSubarctic Ocean Fluxes, R. R. Dickson et al., Eds., Springer, 385-404.

Kwok, R., G. F. Cunningham, M. Wensnahan, I. Rigor, H. J. Zwally, and D. Yi, 2009: Thinning and volume loss of the Arctic Ocean sea ice cover: 2003-2008. Geophys. Res. Lett., 114, C07005, doi:10.1029/2009JC005312.

Lique, C., A. M. Treguier, M. Scheinert, and T. Penduff, 2009: A model-based study of ice and freshwater transport variability along both sides of Greenland. Climate Dyn., 33, 685-705.

,,-- B. Blanke, and N. Grima, 2010: On the origins of water masses exported along both sides of Greenland: A Lagrangian model analysis. Geophys. Res. Lett., 115, C05019, doi:10.1029/ 2009JC005316.

Madec, G., 2008: NEMO Ocean engine. Note du pôle modélisation 27, Institut Pierre-Simon Laplace, 219 pp.

McPhee, M. G., A. Proshutinsky, J. H. Morison, M. Steele, and M. B. Alkire, 2009: Rapid change in freshwater content of the Arctic Ocean. Geophys. Res. Lett., 36, L10602, doi:10.1029/ 2009GL037525.

Peterson, B. J., J. McClelland, R. Curry, R. M. Holmes, J. E. Walsh, and K. Aagaard, 2006: Trajectory shifts in the Arctic and Subarctic freshwater cycle. Science, 313, 1061-1066. 
Pham, D. T., J. Verron, and M. C. Roubaud, 1998: A singular evolutive extended Kalman filter for data assimilation in oceanography. J. Mar. Syst., 16, 323-340.

Polyakov, I. V., and Coauthors, 2008: Arctic Ocean freshwater changes over the past 100 years and their causes. J. Climate, 21, 364-384.

Proshutinsky, A., and Coauthors, 2009: Beaufort gyre freshwater reservoir: State and variability from observations. J. Geophys. Res., 114, C00A10, doi:10.1029/2008JC005104.

Rothrock, D. A., Y. Yu, and G. Maykut, 1999: Thinning of the Arctic sea-ice cover. Geophys. Res. Lett., 26, 3469-3472.

Serreze, M. C., and Coauthors, 2006: The large-scale freshwater cycle of the Arctic. J. Geophys. Res., 111, C11010, doi:10.1029/ 2005JC003424.

Steele, M., and T. Boyd, 1998: Retreat of the cold halocline layer in the Arctic Ocean. J. Geophys. Res., 103, 10 419-10 436.

- and W. Ermold, 2004: Salinity trends on the Siberian shelves. Geophys. Res. Lett., 31, L24308, doi:10.1029/2004GL021302.

_ R. Morley, and W. Ermold, 2001: PHC: A global ocean hydrography with a high-quality Arctic Ocean. J. Climate, 14, 2079-2087.

Swift, J. H., K. Aagaard, L. Timokhov, and E. G. Nikiforov, 2005: Long-term variability of Arctic Ocean waters: Evidence from a reanalysis of the EWG data set. J. Geophys. Res., 110, C03012, doi:10.1029/2004JC002312.

Testut, C., P. Brasseur, J. Brankart, and J. Verron, 2003: Assimilation of sea surface temperature and altimetric observations during 1992-1993 into an eddy permitting primitive equation model of the North Atlantic Ocean. J. Mar. Syst., 40, 291-316.

Thiebaux, J., E. Rogers, W. Wang, and B. Katz, 2003: A new highresolution blended real-time global sea surface temperature analysis. Bull. Amer. Meteor. Soc., 84, 645-656.

Tranchant, B., C.-E. Testut, L. Renault, N. Ferry, F. Birol, and P. Brasseur, 2008: Expected impact of the future SMOS and Aquarius Ocean surface salinity missions in the Mercator Ocean operational systems: New perspectives to monitor ocean circulation. Remote Sens. Environ., 112, 1476-1487.

Troccoli, A., and P. Kallberg, 2004: Precipitation correction in the ERA-40 reanalysis. ERA-40 Project Report Series 13, ECMWF, $10 \mathrm{pp}$.

Våge, K., and Coauthors, 2009: Surprising return of deep convection to the subpolar North Atlantic Ocean in winter 20072008. Nat. Geosci., 2, 67-72.

White, D., and Coauthors, 2007: The Arctic freshwater system: Changes and impacts. J. Geophys. Res., 112, G04S54, doi:10.1029/2006JG000353.

Yashayaev, I., and J. W. Loder, 2009: Enhanced production of Labrador Sea Water in 2008. Geophys. Res. Lett., 36, L01606, doi:10.1029/2008GL036162.

Zhang, J., R. Lindsay, M. Steele, and A. Schweiger, 2008: What drove the dramatic retreat of Arctic sea ice during summer 2007. Geophys. Res. Lett., 35, L11505, doi:10.1029/2008GL034005. 